\title{
Emulsifying ability of exudate gums obtained from three plant species in Ghana
}

\author{
Owusu John ${ }^{1}$, Oldham J. H. ${ }^{2}$, Oduro $\mathrm{I}^{2}$., Ellis W. O. ${ }^{2}$, Owusu-Boateng G. ${ }^{3}$ \\ ${ }^{1}$ Koforidua Technical University, , Koforidua, Ghana, Faculty of Applied Science and Technology \\ ${ }^{2}$ Kwame Nkrumah University of Science and Technology, Kumasi, Ghana, Department of Biochemistry, \\ ${ }^{3}$ Kwame Nkrumah University of Science and Technology, Kumasi, Ghana, Department of Fisheries
}

\begin{abstract}
Food emulsions are thermodynamically unstable mixtures which can be stabilized with the application of an emulsifier. In Ghana emulsifiers are imported, and this increases the final cost of food emulsions. In this study, gums obtained from three tree plant species in Ghana, i.e. Albizia zygia (Albizia), Khaya senegalensis (Khaya), and Anarcardium occidentale (Cashew), were used to stabilize oil-in-water emulsion, and the stability of the emulsions were measured after centrifugation at $1300 \mathrm{x}$ g for $5 \mathrm{~min}$, and upon $\mathrm{pH}$ adjustment (from 2 to 3.5). Quantity of gum (mass), solubility of gum in the continuous phase, viscosity, oil volume fraction, and $\mathrm{pH}$ were investigated to determine how they affect emulsion stability. The results indicated with the exception of viscosity, emulsion stability is influenced by all the other factors studied. In addition there was no significant difference $(\mathrm{P}<0.05)$ between the emulsion stabilities of food emulsions stabilized by gums of Cashew (0.77-0.86) and Acacia (0.78-0.87). The Pearson's co-efficient of correlation indicated that the emulsion stability values of the emulsions positively correlated with the solubility of the gums $\left(\mathrm{R}^{2}=0.983\right.$ at $\mathrm{P}<0.05$, and0.997 at $\left.\mathrm{P}<0.01\right)$. Although there were no significant differences in the emulsion stability values of emulsions stabilized with Albizia and Khaya gums, both recorded significantly lower $(\mathrm{P}<0.05)$ emulsion stability values $(0.76-0.85$ and $0.75-0.81$ respectively) than the Acacia gum (control). The Cashew gum has the potential to be utilized as an emulsifier in the food industry.
\end{abstract}

Keywords: Emulsion, Emulsifier, Acacia gum, Oil-in-water Emulsion, Emulsion stability

\section{Introduction}

Food emulsions are dispersions of one liquid in another (McClements, 2016). Many foods such as milk, yoghurt, and beverages occur in the form of oilin-water $(\mathrm{O} / \mathrm{W})$ emulsions, where small oil droplets are dispersed in water (Grigoriev and Miller, 2009). Generally emulsions are thermodynamically unstable (Technical Brief, 2011). The instability of emulsions is caused by factors such as gravitational separation, flocculation, coalescence, and Ostwald ripening (McClements, 2016). In unstable emulsions sedimentation occurs, and this reduces the consumer appeal of the product. This instability could reduce the shelf life of food emulsions. Conversely, stabilizing food emulsions can help increase their shelf life (Buffo et al., 2001). Therefore many methods have been designed to enhance the stability of food emulsions, but the common among these is the application of emulsifiers such as gums (Stauffer,
1999). The emulsifier is a surface-active substance, and has the ability to adsorb at the oil-water interface to aid in droplet formation and stabilization through the generation of repulsive forces (McClements, 2016). In order to assess the effectiveness of an emulsifier, the emulsion is subjected to disturbances such as heating, addition of electrolyte, and centrifugation (McClements, 2016). The use of gum emulsifiers is influenced by factors such as solubility of gum, viscosity of gum solution, surface tension and oil-volume fraction of emulsion, and protein content of gum (Imeson, 1992; Damodoran, 1996).

Application of gums in the food industry is influenced by their functional properties. They may be used as binding agents, bulking agents, foam stabilizers, protective colloids, syneresis inhibitors, clarifying agents, emulsifiers, etc (Damodoran, 1996). Studies on emulsifying functionality of gums have been reported and most of them have made use of 
Acacia gum (Sabah El-Kheir et al., 2008; Samanta et al., 2010), xanthan gum (Krstonošić et al., 2015) gum tragacanth and gum karaya (Samanta et al., 2010). The price of Acacia gum is $\$ 1,500$ per ton, gum karaya is $\$ 2,250-\$ 6,000$, and gum tragacanth is $\$ 3,000$ - $\$ 4,000$ (Nussinovitch, 2010). Due to the expensive nature of these gums and their irregular supply pattern, many authors have explored the possibility of using alternatives such as starch, soy protein isolate (Achouri et al., 2012), flaxseed protein concentrate, and soybean protein concentrate together with Acacia gum (Wang et al., 2011), to stabilize oil-in-water $(\mathrm{O} / \mathrm{W})$ emulsions.

In Ghana, the current use of Albizia and Khaya trees are mainly for timber production, Cashew is grown widely and is mainly for its nuts. The gums produced by these tree species have not been exploited and utilized probably due to lack of data on their utilization. It is against this background that this research was done to determine the factors which influence the application of gums in oil-in-water emulsions and to assess the stability of emulsions stabilized by gums obtained from three tree species in Ghana, in order to determine their suitability in the utilization in the food industry.

\section{Methodology}

\subsection{Source of gums}

The Cashew gum (Anarcardium occidentale) was collected from a Cashew farm at Ejura in the Ashanti Region. Albizia (Albizia zygia) and Khaya (Khaya senegalensis) were obtained from a forest in Juaso, and the Acacia gum (Acacia species) which served as the control was obtained from the Forest Research Institute of Ghana (FORIG). The gums were collected in the dry season.

\subsection{Processing of gums}

The gums were sorted to remove debris, dirt and pieces of wood from them. They were then dried in the sun for 2 weeks. They were ground into powder, and then used for the emulsion stability experiment.

\subsection{Viscosity of gums}

Three percent (w/v) of each gum exudate was prepared and the Brookfield Viscometer (Model DVII+ Version 3.0) used to determine the viscosity at $100 \mathrm{rpm}$ as described in a previous study (Owusu et al., 2005).

\section{$2.4 \mathrm{pH}$ of the gums}

Two grams of the gums was dispersed in $100 \mathrm{~mL}$ of distilled water at room temperature. A standardized $\mathrm{pH}$ meter (HI9024 Microcomputer) was used to determine the $\mathrm{pH}$ of the gum exudates (Sadler and Murphy, 2010).

\subsection{Solubility of gums}

A centrifuge tube was dried and weighed, $1 \mathrm{~g}$ of exudate gum was placed in it and $40 \mathrm{~mL}$ distilled water added. The resulting solution was stirred constantly and centrifuged at $2200 \mathrm{rpm}$ for $15 \mathrm{~min}$ (Damodoran, 1996). A glass crucible was weighed and the supernatant solution transferred into it, and then evaporated to dryness. The solubility was then determined in triplicates using the formulae:

$\%$ Solubility $=\frac{\text { Weight of soluble gum exudate } \mathrm{x} 100 \%}{\text { Weight of sample (dry basis })}$

\subsection{Emulsion stability}

The stability of oil-in-water (O/W) emulsion stabilized with the various gums was assessed using a centrifuge (McClements, 2016) and $\mathrm{pH}$ adjustment (Samanta et al., 2010).

\subsection{Centrifuge method}

Vegetable cooking oil (Frytol) and water were used to prepare $\mathrm{O} / \mathrm{W}$ emulsion. The emulsion was prepared using the method of Stauffer (1980). Briefly, O/W emulsions of ratios $3 / 15$ and 4/25 were prepared using a blender (Kenwood Chef Excel, JKP 280 Series). O/W emulsion of ratios $3 / 15$ (oil volume fraction, $16.7 \%$ ) and $4 / 25$ (oil volume fraction, $13.8 \%$ ) were each blended with $0.2,0.3$, and $0.4 \mathrm{~g}$ of A. species, $A$. occidentale, $K$. senegalensis, and $A$. yygia gum powders. The solution was then placed in a graduated centrifuge tube. The solution was centrifuged at $1300 \mathrm{x}$ g for $5 \mathrm{~min}$. The volume of the separated cream phase was read from the graduated centrifuge tube and expressed as a ratio of the total volume. Emulsion stability was calculated using the formula proposed by Damodoran (1996):

Emulsion stability $=\frac{\text { Volume of cream layer }}{\text { Total volume of emulsion }}$ All determinations were made in triplicates. 


\section{$2.8 \mathrm{pH}$ adjustment method}

The $\mathrm{pH}$ of $\mathrm{O} / \mathrm{W}$ emulsions stabilized with $0.4 \mathrm{~g}$ of each of the exudate gum studied was adjusted to two $\mathrm{pH}$ levels, i.e. 2.0 and 3.5 using dilute hydrochloric acid ( $\mathrm{HCl})$. The volume of the cream layer was determined and the stability of the emulsions was calculated using a previously proposed formula (Damodoran, 1996).

\subsection{Experimental design and data analysis}

The factors which were investigated to determine how they affect emulsion stability were the quantity of gum (mass), solubility of gum in the continuous phase, oil volume fraction, and $\mathrm{pH}$. The data obtained were analyzed using Analysis of Variance (ANOVA), and differences in means were deemed to be significant at $\mathrm{P}<0.05$.

\section{Results and Discussion}

\subsection{Effect of type of gum on emulsion stability}

In this study, two emulsions of different oil-to-water ratio were used. The emulsion stability (ES) values of the emulsions prepared with $3 \mathrm{~mL}$ oil and $15 \mathrm{~mL}$ water (with oil volume fraction 16.7\%) and stabilized with the gum exudates studied are shown in Table 1. At each gum quantity, the ES

\section{Table 1}

Effect of type and quantity of gum exudates on ES ( $3 \mathrm{~mL}$ oil: $15 \mathrm{~mL}$ water, oil volume fraction 16.7\%)

\begin{tabular}{llll}
\hline Mass of gum $(\mathrm{g})$ & $\mathbf{0 . 2}$ & $\mathbf{0 . 3}$ & $\mathbf{0 . 4}$ \\
\hline Acacia & $0.78 \pm 0.00^{\mathrm{a} \alpha}$ & $0.80 \pm 0.20^{\mathrm{a} \beta}$ & $0.82 \pm 0.10^{\mathrm{a} \mu}$ \\
Cashew & $0.77 \pm 0.20^{\mathrm{ab} \alpha}$ & $0.79 \pm 0.00^{\mathrm{ab} \beta}$ & $0.81 \pm 0.10^{\mathrm{ab} \mu}$ \\
Albizia & $0.76 \pm 0.10^{\mathrm{b} \alpha}$ & $0.78 \pm 0.00^{\mathrm{b} \beta}$ & $0.80 \pm 0.00^{\mathrm{b} \mu}$ \\
Khaya & $0.75 \pm 0.10^{\mathrm{bc} \alpha}$ & $0.77 \pm 0.00^{\mathrm{bc} \beta}$ & $0.79 \pm 0.10^{\mathrm{bc} \mu}$ \\
\hline
\end{tabular}

Means with different alphabets are significant at $\mathrm{P}<0.05$ in a column. Means with different Greek letters in a row indicate significant difference at $\mathrm{P}<0.05$.

value of Acacia (Control) and the Cashew gums were not different $(\mathrm{P}<0.05)$, but those of Albizia and Khaya gums were different. The ES values for the emulsion prepared with $4 \mathrm{~mL}$ water and $25 \mathrm{~mL}$ oil (oil volume constitute $13.8 \%$ ) also showed similar results (Table 2). The higher solubility values of Acacia and
Cashew gums (Table 3) may account for their high ES values. Solubility of an emulsifier in an emulsion is known to influence its emulsion stability (Damodoran, 1996). There was a high positive correlation $\left(\mathrm{R}^{2}=0.983\right.$ at $\mathrm{P}<0.05$, and $\mathrm{R}^{2}=0.997$ at $\mathrm{P}<0.01)$ between solubility and emulsion stability for emulsions of oil-water ratio 3:15 (oil)

Table 2

Effect of type and quantity of gum exudates on ES (4mL oil: $25 \mathrm{~mL}$ water, oil volume fraction $13.8 \%$ )

\begin{tabular}{llll}
\hline Mass of gum $(\mathrm{g})$ & $\mathbf{0 . 2}$ & $\mathbf{0 . 3}$ & $\mathbf{0 . 4}$ \\
\hline Acacia & $0.86 \pm 0.20^{\mathrm{a} \alpha}$ & $0.87 \pm 0.10^{\mathrm{a} \alpha}$ & $0.87 \pm 0.20^{\mathrm{a} \alpha}$ \\
Cashew & $0.83 \pm 0.10^{\mathrm{b} \alpha}$ & $0.85 \pm 0.00^{\mathrm{b} \beta}$ & $0.86 \pm 0.20^{\mathrm{ab} \beta}$ \\
Albizia & $0.80 \pm 0.20^{\mathrm{c} \alpha}$ & $0.83 \pm 0.20^{\mathrm{c} \beta}$ & $0.85 \pm 0.10^{\mathrm{b} \mu}$ \\
Khaya & $0.78 \pm 0.00^{\mathrm{d} \alpha}$ & $0.80 \pm 0.10^{\mathrm{d} \beta}$ & $0.81 \pm 0.20^{\mathrm{c} \beta}$ \\
\hline
\end{tabular}

Means with different alphabets are significant at $\mathrm{P}<0.05$ in a column. Means with different Greek letters in a row indicate significant difference at $\mathrm{P}<0.05$.

volume constitutes $16.7 \%$ ) and 4:25 (oil volume constitutes $13.8 \%$ ) respectively (Tables 4 and 5). The results indicate that Cashew gum could be used as a better substitute for Acacia gum in oil-in-water emulsions (such as milk, yoghurt, and orange juice) than Khaya and Albizia gums.

\subsection{Effect of gum quantity on emulsion stability}

In the present study, as the quantity of gum exudate in the emulsions increased the ES values 
Table 3

Physicochemical properties of gum exudates

\begin{tabular}{llll}
\hline Gum exudate & $\mathrm{pH}$ & $\%$ Solubility & Viscosity (mPas) at 3\% concentration) \\
\hline Acacia & $5.00 \pm 0.20^{\mathrm{a}}$ & $81.87 \pm 3.00^{\mathrm{a}}$ & $93.0 \pm 4.0^{\mathrm{a}}$ \\
Cashew & $4.10 \pm 0.30^{\mathrm{c}}$ & $72.57 \pm 3.00^{\mathrm{a}}$ & $210.0 \pm 4.0^{\mathrm{c}}$ \\
Albizia & $4.50 \pm 0.10^{\mathrm{b}}$ & $62.71 \pm 2.00^{\mathrm{b}}$ & $11195.0 \pm 3.0^{\mathrm{b}}$ \\
Khaya & $3.80 \pm 0.10^{\mathrm{d}}$ & $43.85 \pm 3.00^{\mathrm{b}}$ & $5204 \pm 3.0^{\mathrm{d}}$ \\
\hline
\end{tabular}

Means in each column are significant at $\mathrm{P}<0.05$

also showed increasing trend (Tables 1 and 2). Emulsifier concentration is known to influence emulsion stability (McClements, 2016). This might be due to the fact that greater amount of gum can provide enough coating for the dispersed phase to prevent coalescence. Similar results were reported for $\mathrm{O} / \mathrm{W}$ emulsions stabilized with various types of gums (Sun et al., 2007; Sabah El-Kheir et al., 2008; Wang et al., 2011; Mahfoudhi et al., 2012; Almeida et al. 2015).

Table 4

Correlation between solubility of gum exudates and ES (3mL oil: 15mL water, oil volume fraction 16.7\%)

\begin{tabular}{llrr}
\hline & & Solubility & Emulsion stability \\
\hline Solubility & Pearson Correlation & 1 & $.983^{*}$ \\
& Sig. (2-tailed) & & .017 \\
& $\mathrm{~N}$ & 4 & 4 \\
Emulsion stability & Pearson Correlation & $.983^{*}$ & .017 \\
& Sig. (2-tailed) & 4 & 4 \\
& $\mathrm{~N}$ & & 4 \\
\hline
\end{tabular}

Correlation is significant at 0.05 level (2-tailed)

Table 5

Correlation between solubility of gum exudates ES (4mL oil: $25 \mathrm{~mL}$ water, oil volume fraction $13.8 \%$ )

\begin{tabular}{llrr}
\hline & & Solubility & Emulsion stability \\
\hline Solubility & Pearson Correlation & 1 & $.997^{* *}$ \\
& Sig. (2-tailed) & & .003 \\
& $\mathrm{~N}$ & 4 & 4 \\
Emulsion stability & Pearson Correlation & $.997^{* *}$ & 1 \\
& Sig. (2-tailed) & .003 & 4 \\
\hline
\end{tabular}

Correlation is significant at 0.01 level (2-tailed)

\subsection{Effect of viscosity on emulsion stability}

Viscosity of the continuous phase of an $\mathrm{O} / \mathrm{W}$ emulsion may influence its ES value. The results on the correlation between viscosity and ES are shown in Tables 6 and 7. When emulsions of different volume fractions were stabilized with the various gums of different viscosities it was found out that viscosity had negative correlation with emulsion stability $(\mathrm{R}=-0.647$ and -0.392$)$ which was not significant $(\mathrm{P}>0.05)$. This means that the stability of the emulsions was not influenced by viscosity of the gums. The results are in consonance with those reported by Desplanques et al. (2012), but contrary to those of other authors (Paraskevopoulou et al., 2005; Wang et al., 2011; Gavlighi et. al., 2013). The difference may stem from the differences in the gums utilized in the studies. 
Table 6

Correlation between viscosity and ES ( $3 \mathrm{~mL}$ oil: $15 \mathrm{~mL}$ water, oil volume fraction $16.7 \%$ )

\begin{tabular}{llrr}
\hline & & Viscosity & Emulsion stability \\
\hline Viscosity & Pearson Correlation & 1 & -.647 \\
& Sig. (2-tailed) & & .353 \\
& $\mathrm{~N}$ & 4 & 4 \\
Emulsion stability & Pearson Correlation & -.647 & 1 \\
& Sig. (2-tailed) & .353 & 4 \\
& $\mathrm{~N}$ & 4 & \\
\hline Correlation is significant at 0.05 level (2-tailed) & &
\end{tabular}

\subsection{Effect of oil volume fraction on emulsion stability}

The oil volume fraction of the emulsions influenced their ES values (Tables 1 and 2). The ES

values for the emulsions of greater oil volume fraction, $3 \mathrm{~mL}$ oil: $15 \mathrm{~mL}$ water (oil volume constitutes $16.7 \%$ ) were generally lower than those of lower oil volume fraction, $4 \mathrm{~mL}$ oil: $25 \mathrm{~mL}$ water (oil volume constitutes $13.8 \%$ ). The results collaborates those of a previous study where an increase in oil volume fraction of an emulsion led to a decrease in emulsion stability (Dlużewska et al., 2006). In another study, lower level of oil volume fraction was reported to favour emulsion stability than higher oil content (Sargolzaei et al., 2011). Imeson (1992) has indicated that an emulsion of greater oil volume fraction requires more gum to stabilize it than that of lower oil volume fraction.

\subsection{Effect of $p H$ changes on emulsion stability}

The effect of $\mathrm{pH}$ of the emulsion on ES was also investigated (Tables 8 and 9). The results indicated that for each gum-stabilized emulsion, a reduction in $\mathrm{pH}$ led to a reduction in $\mathrm{ES}$ values

Table 7

Correlation between viscosity and ES ( $4 \mathrm{~mL}$ oil: $25 \mathrm{~mL}$ water, oil volume fraction $13.8 \%$ )

Viscosity Emulsion stability

\begin{tabular}{llrr}
\hline Viscosity & Pearson Correlation & 1 & -.392 \\
& Sig. (2-tailed) & & .608 \\
& $\mathrm{~N}$ & -.392 & 4 \\
Emulsion & Pearson Correlation & .608 & 1 \\
stability & Sig. (2-tailed) & 4 & 4 \\
& $\mathrm{~N}$ & &
\end{tabular}

$(\mathrm{P}<0.05)$ for emulsions prepared with different oil volume fractions. The reduced $\mathrm{pH}$ might have led to the removal of some of the protective film which surrounds the dispersed oil phase, leading to some amount of flocculation and coalescence. Generally, Cashew gum-stabilized emulsions were more stable in acidic medium than emulsions stabilized with
Khaya and Albizia gums, indicating that Cashew gum could potentially be utilized in acidic beverages such as fruit juices (Nussinovitch, 2010). A previous study found out that emulsions were more stable in the $\mathrm{pH}$ range 5-8 when almond tree (Prunus dulcis) emulsifier was applied (Mahfoudhi et al., 2012). 
Table 8

Effect of $\mathrm{pH}$ on ES (3mL oil: $15 \mathrm{~mL}$ water, oil volume fraction $16.7 \%$ )

\begin{tabular}{lll}
\hline $\mathrm{pH}$ & $\mathbf{2 . 0}$ & $\mathbf{3 . 5}$ \\
\hline Acacia & $0.86 \pm 0.20^{\mathrm{a} \alpha}$ & $0.88 \pm 0.20^{\mathrm{b} \alpha}$ \\
Cashew & $0.83 \pm 0.00^{\mathrm{a} \beta}$ & $0.87 \pm 0.20^{\mathrm{b} \alpha}$ \\
Albizia & $0.80 \pm 0.20^{\mathrm{a} \mu}$ & $0.86 \pm 0.20^{\mathrm{b} \mu \alpha}$ \\
Khaya & $0.79 \pm 0.10^{\mathrm{a} \mu}$ & $0.85 \pm 0.00^{\mathrm{b} \mu}$ \\
\hline
\end{tabular}

Means with different alphabets in the same row are significant at $\mathrm{P}<0.05$. Means with different Greek letters in a column indicate significant difference at $\mathrm{P}<0.05$.

Table 9

Effect of $\mathrm{pH}$ on $\mathrm{ES}$ ( $4 \mathrm{~mL}$ oil: $25 \mathrm{~mL}$ water, oil volume fraction $13.8 \%$ )

\begin{tabular}{lll}
\hline $\mathrm{pH}$ & $\mathbf{2 . 0}$ & $\mathbf{3 . 5}$ \\
\hline Acacia & $0.86 \pm 0.00^{\mathrm{a} \alpha}$ & $0.88 \pm 0.00^{\mathrm{b} \alpha}$ \\
Cashew & $0.83 \pm 0.20^{\mathrm{a} \beta}$ & $0.86 \pm 0.00^{\mathrm{b} \beta \mu}$ \\
Albizia & $0.73 \pm 0.00^{\mathrm{a} \mu}$ & $0.87 \pm 0.20^{\mathrm{b} \alpha \beta}$ \\
Khaya & $0.72 \pm 0.00^{\mathrm{a} \mu}$ & $0.85 \pm 0.10^{\mathrm{b} \mu}$ \\
\hline
\end{tabular}

Means with different alphabets in the same row are significant at $\mathrm{P}<0.05$. Means with different Greek letters in a column indicate significant difference at $\mathrm{P}<0.05$.

\section{Conclusions}

The results of the study have shown that ES of the emulsions were influenced by type of gum, quantity of gum, solubility of gum in the continuous phase, oil volume fraction, and $\mathrm{pH}$. In addition Cashew gum has similar emulsion stability values as Acacia gum, therefore it can be used as a substitute for Acacia gum to stabilize oil-in-water emulsions.

\section{References}

Achouri, A., Zamani, Y., and Boye, J. I. (2012). Stability and physical properties of emulsions prepared with and without soy proteins. Journal of Food Research, 1 (1), pp 254-267.

Almeida, T. C. A., Larentis, A. L., and Ferraz, H. C. (2015). Evaluation of the Stability of Concentrated Emulsions for Lemon Beverages Using Sequential Experimental Designs.

PLoS ONE 10(3), pp 1-18.

Buffo, R. A., Reineccius, G. A., and Oehlert, G. W. (2001). Factors affecting the emulsifying and rheological properties of gum acacia in beverage emulsions. Food Hydrocolloids, 15, pp 53-66.

Damodoran, S. (1996). Amino acids, peptides and proteins. In: R. F. Owen (Ed.) Food Chemistry. Marcel Dekker Inc. New York, Basel, pp 377-378.

Desplanques, S., Renou, F., Grisel, M., and Malhiac, C. (2012). Impact of chemical composition of xanthan and acacia gums on emulsification and stability of oil-in-water emulsion. Food Hydrocolloids, 27 (2), pp 401 410.

Dlużewska, E., Stobiecka, A., Maszewska, M. (2006). Effect of oil phase concentration on rheological properties and stability of beverage emulsions. Acta Scientiarum Polonorum, Technologia Alimentaria, 5 (2), pp 147-156.

Gavlighi, H. A., Meyer, A. S., Zaidel, D. N. A., Mohammadifar, M. A., and Mikkelsen, J. D. (2013). Stabilization of emulsions by gum tragacanth (Astragalus spp.) correlates to the galacturonic acid content and methoxylation degree of the gum. Food Hydrocolloids, 31, pp 5-14.

Grigoriev, D. O., and Miller, R. (2009). Mono- and multilayer covered drops as carriers, Current Opinion in Colloid and Interface Science, 14, pp 48-59.

Imeson, A. (1992). Thickening and gelling agents for food. Chapman and Hall, London.

Krstonošić, V., Dokić, L., Nikolić, I., and Milanović, M. (2015). Influence of xanthan gum on oil-in-water emulsion characteristics stabilized by OSA starch. Food Hydrocolloids, 45, pp 9-17.

Mahfoudhi,N.,Chouaibi, M., Dons, F., Ferrari, G., and Hamdi, S. (2012). Chemical composition and functional properties of gum exudates from the trunk of the almond tree (Prunus dulcis). Food Science and Technology international, 18 (3), pp 241-250. 
McClements, D. J. (2016). Food emulsions principles, practices and techniques. $3^{\text {rd }}$ ed. Taylor \&

Francis Group, LLC. New York.

Nussinovitch, A. (2010). Plant gum exudates of the world:

Sources, distribution, properties and applications. CRC Press, Taylor and Francis

Group, New York.

Owusu, J., Oldham, J. H., Oduro, I., Ellis, W. O., and Barimah, J. (2005). Viscosity studies of Cashew gum. Tropical Science, 45, pp 86-89.

Paraskevopoulou, A., Boskou, D., and Kiosseoglou, V. (2005). Stabilization of olive oil-lemon juice emulsion with polysaccharides. Food Chemistry, 90, pp 627-634.

Sabah El-Kheir, M. K., Yagoub, A. E. G. A., and Baker, A. A. A. (2008). Emulsion-stabilizing effect of gum from Acacia Senegal (L) Wild. The role of quality and grade of gum, oil type, temperature, stirring time and concentration. Pakistan Journal of Nutrition, 7 (3), pp 395-399.

Sadler, G. D., and Murphy, P. A. (2010). pH and titratable acidity. In: S. S. Nielsen (Ed.). Food Analysis. Springer Science + Business Media, LLC2010, New York, pp 220-238.
Samanta, A., Ojha, D., and Mukherjee, B. (2010). Stability analysis of primary emulsion using a new emulsifying agent gum odina. Natural Science. 2 (5), pp 494-505.

Sargolzaei, J., Mosavian, M. T. H., and Hassani, A. (2011). Modelling and simulation of high power ultrasonic process in preparation of stable oil-in-water emulsion. Journal of Software Engineering and Applications, 4, pp 259267.

Stauffer, K. R. (1980). Gum tragacanth. In: R. L. Davidson (Ed.), Handbook of water-soluble gums and resins, McGraw-Hill, New York, pp 1-31.

Stauffer, C. E. (1999). Emulsifiers: Practical Guides for the Food Industry, Eagen Press, St. Paul, USA.

Sun, C., Gunasekaran, S., and Richards, M. P. (2007). Effect of xanthan gum on physicochemical properties of whey protein isolate stabilized oil-in-water emulsions. Food Hydrocolloids, 21, pp 555-564.

Wang, B., Wang, L-J, Dong, L., Adhikari, B., Shi, J. (2011). Effect of gum Arabic on stability of oil-in-water emulsion stabilized by flaxseed and soybean protein. Carbohydrate Polymers, 86, pp 343-351. 